\title{
Neonatal Hypoglycaemia and Visual Development: A Review
}

\author{
Nabin Paudel ${ }^{\mathrm{a}}$ Arijit Chakraborty ${ }^{\mathrm{a}, \mathrm{b}} \quad$ Nicola Anstice $^{\mathrm{a}}$ \\ Robert J. Jacobs ${ }^{\text {a }}$ Jo E. Hegartyc, d Jane E. Harding ${ }^{c}$ \\ Benjamin Thompson ${ }^{a, b}$ for the CHYLD Study Group \\ a School of Optometry and Vision Science, The University of Auckland, Auckland, New Zealand; b School of \\ Optometry and Vision Science, University of Waterloo, Waterloo, ON, Canada; ' Liggins Institute, The University of \\ Auckland, and d Newborn Services, Auckland City Hospital, Auckland, New Zealand
}

\section{Keywords}

Neonatal hypoglycaemia · Vision · Visual function · Visual processing Brain injury $\cdot$ Neurodevelopment . Occipital cortex

\begin{abstract}
Background: Many newborn babies experience low blood glucose concentrations, a condition referred to as neonatal hypoglycaemia $(\mathrm{NH})$. The effect of $\mathrm{NH}$ on visual development in infancy and childhood is of interest because the occipital lobes, which include the primary visual cortex and a number of extrastriate visual areas, may be particularly susceptible to $\mathrm{NH}$-induced injury. In addition, a number of case series have suggested that $\mathrm{NH}$ can affect eye and optic nerve development. Objective: To review the existing literature concerning the effect of $\mathrm{NH}$ on the visual system. Methods: A PubMed, Embase, Medline, and Google Scholar literature search was conducted using prespecified MeSH terms. Results: The literature reviewed revealed no clear evidence for an effect of $\mathrm{NH}$ on the development of the eye and optic nerve. Furthermore, occipital and occipital-parietal lobe injuries following $\mathrm{NH}$ often occurred in conjunction with comorbid conditions and were not clearly linked to subsequent visual dysfunction, possibly due to difficulties in measuring vision in young children and a lack of studies at older
\end{abstract}

\section{KARGER}

(C) 2017 S. Karger AG, Basel

E-Mail karger@karger.com

www.karger.com/neo ages. A recent, large-scale, prospective study of $\mathrm{NH}$ outcomes at 2 years of age found no effect of mild-to-moderate $\mathrm{NH}$ on visual development. Conclusion: The effect of $\mathrm{NH}$ on visual development is unclear. It is currently unknown whether $\mathrm{NH}$ affects visual function in mid-to-late childhood when many visual functions reach adult levels.

(c) 2017 S. Karger AG, Basel

After birth, maternal glucose delivery across the placenta ceases and neonatal blood glucose concentrations fall, before rising again after the first few hours to reach adult concentrations around day 3 . However, between 5 and $15 \%$ of newborn babies experience low blood glucose concentrations, a condition referred to as neonatal hypoglycaemia (NH) [1]. Risk factors for NH include maternal diabetes, preterm birth, and being small or large for gestational age. NH may be accompanied by symptoms such as seizures, but is also commonly asymptomatic. Therefore, it is usual for at-risk babies to undergo blood glucose monitoring and to be treated for $\mathrm{NH}$ if their blood glucose concentration falls below a specific threshold. A threshold of $2.6 \mathrm{mmol} / \mathrm{L}$ is widely used [2,3], and children treated at this threshold have recently been reported to have normal neurologic outcomes at 2 years of age [4]. Periods of severe $\mathrm{NH}$ are associated with brain lesions and im- 
paired neurodevelopment [5], and mild episodes of $\mathrm{NH}$ may also be associated with abnormal neurodevelopment [6]. The impact of $\mathrm{NH}$ on vision is of interest as $\mathrm{NH}$ may preferentially damage the occipital-parietal region of the brain that is centrally involved in visual processing [7].

Here we review the literature relating $\mathrm{NH}$ to the development and function of the visual pathway. Blood glucose concentrations, patient age ranges, and the presence or absence of symptoms are provided at the first mention of each study if this information was available.

We searched PubMed, Embase, Medline, and Google Scholar using the following MeSH terms: neonatal hypoglycaemia and brain injury, neonatal hypoglycaemia and vision or visual development or ophthalmological findings, neonatal hypoglycaemia and cortical/cerebral visual impairment, and neonatal hypoglycaemia and neurodevelopment. The search was completed in June 2016. Primary research articles written in English that reported data from patients of any age who had experienced hypoglycaemia during the neonatal period ( $<1$ month of age) were included in this review. No restriction was placed on the age of the published articles. We found that the literature on $\mathrm{NH}$ and vision is dated, with only 5 contemporary studies ( $<5$ years old) identified. This was surprising given that $\mathrm{NH}$ and impaired vision are often linked in the general literature relating to $\mathrm{NH}$.

\section{Neonatal Hypoglycaemia and Ocular Development}

Two older case-series studies have linked NH to cataract $[8,9]$. For example, in a case series of 13 children with cataracts and documented episodes of low blood glucose concentrations at different ages, 3 children had experienced $\mathrm{NH}(0.6-1.1 \mathrm{mmol} / \mathrm{L})$ [9]. Cataract formation following hypoglycaemia $(<2.0 \mathrm{mmol} / \mathrm{L})$ in the adult rat has been linked to low aqueous humour glucose concentrations and reduced concentrations of adenosine triphosphate, a coenzyme that contributes to lens transparency [10]. However, it is unknown whether similar effects occur in humans. In fact, more recent studies have not identified an association between $\mathrm{NH}$ and cataract [11], and an older follow-up study of children between the ages of 1 and 4 years who had experienced $\mathrm{NH}(<1.66 \mathrm{mmol} / \mathrm{L})$ reported cataract in only 1 of 151 cases [6]. Furthermore, any association between $\mathrm{NH}$ and cataract could be due to a common underlying risk factor such as low birth weight [12].

Optic nerve hypoplasia has also been associated with $\mathrm{NH}$. A retrospective review of patients with optic nerve hypoplasia [13] found that 6 of 51 children (12\%) had ex- perienced $\mathrm{NH}(<1.38 \mathrm{mmol} / \mathrm{L}$ for preterm and $<1.94$ $\mathrm{mmol} / \mathrm{L}$ for full-term babies). However, a larger prospective study of optic nerve hypoplasia revealed that only 5 of 93 (5\%) children with optic nerve hypoplasia had experienced NH [14].

Optic nerve hypoplasia originates in utero $[15,16]$. Therefore, any association between $\mathrm{NH}$ and optic nerve hypoplasia is likely to be indirect. Interestingly, a study of children born to diabetic mothers [17] reported a relatively high prevalence of optic nerve hypoplasia (17 of 93 patients) compared to the general population (7-10 per $100,000)[15,18]$. This suggests that certain conditions may increase the risk of both $\mathrm{NH}$ and optic nerve hypoplasia since $50 \%$ of babies born to diabetic mothers will develop $\mathrm{NH}$ [19].

Macular hypoplasia [20], bilateral optic atrophy [21], and congenital glaucoma [22] have also been reported in cases of $\mathrm{NH}$. However, these children had experienced a range of comorbid conditions, making it unclear whether $\mathrm{NH}$ was directly related to the ocular pathologies.

In summary, a link between $\mathrm{NH}$ and ocular development has not yet been clearly demonstrated.

\section{Neonatal Hypoglycaemia and Refractive Error}

The refractive status of children with a history of $\mathrm{NH}$ has been described in 2 studies. Koivisto et al. [6] assessed 151 children from 1 to 4 years of age who had experienced hypoglycaemia after birth $(<1.66 \mathrm{mmol} / \mathrm{L})$. Of these, 1 child who had experienced symptomatic hypoglycaemia with convulsions had high myopia associated with zonular cataract, and 1 who had experienced asymptomatic hypoglycaemia had high hyperopia. Karimzadeh et al. [23] reported a higher proportion of refractive error, with 6 of 27 Iranian children (22\%) who had experienced NH $(<1.1$ $\mathrm{mmol} / \mathrm{L}$ ) having a refractive error (type unspecified) at a mean age of 3.5 years. However, this prevalence of refractive errors is similar to that reported among school-aged children in Iran (27\%) [24]. Therefore, there is no current evidence for a clear link between $\mathrm{NH}$ and refractive error.

\section{Neonatal Hypoglycaemia and Binocular Vision}

Three studies have indicated a possible association between $\mathrm{NH}$ and strabismus. Koivisto et al. [6] reported strabismus in 10 of $144(7 \%)$ children aged $1-4$ years with a history of $\mathrm{NH}(<1.1 \mathrm{mmol} / \mathrm{L} ; 7$ symptomatic, 3 asymptomatic). However, this rate of strabismus was compa-
48

Neonatology 2017;112:47-52 DOI: $10.1159 / 000456705$
Paudel et al. 
rable to their nonhypoglycaemic control group ( 3 of 54, or $6 \%$ ), suggesting that $\mathrm{NH}$ may not have been a contributing factor. Murakami et al. [25] reported strabismus (type unspecified) in 1 of 8 children (13\%) at a mean age of 4 years who had experienced symptomatic $\mathrm{NH}(<1.1$ $\mathrm{mmol} / \mathrm{L}$ ), and Yalnizoglu et al. [21] found that alternating exotropia was present at a mean age of 3 years in 1 of 13 children (8\%) with a history of symptomatic NH. Small sample sizes make it difficult to draw strong conclusions from these studies. Furthermore, strabismus is common following neurological insults and therefore comorbid conditions other than $\mathrm{NH}$ may have contributed to these associations. Nystagmus has also been reported in a small number of infants with a history of $\mathrm{NH}$ [6]; however, as with strabismus, a direct link with $\mathrm{NH}$ has not been established.

\section{Neonatal Hypoglycaemia and Brain Injury}

Severe or prolonged NH can result in ischaemic and atrophic brain injury, affecting the cortex and underlying white matter [5]. Case and retrospective cohort studies involving brain imaging have suggested that the occipital and posterior parietal lobes are particularly susceptible to brain injury associated with $\mathrm{NH}[7,20,26]$. For example, $\mathrm{NH}(<2.2 \mathrm{mmol} / \mathrm{L})$ was identified as the primary cause of brain injury in 13 of 21 infants with occipital lobe abnormalities [27].

Brain imaging data from case and cohort studies of $\mathrm{NH}$ are difficult to interpret due to the high prevalence of comorbid conditions such as hypoxia-ischaemia or intrauterine growth restriction, both of which are also associated with brain injury $[5,21,28]$. In addition, a mechanism that could explain an association between posterior brain injury and $\mathrm{NH}$ has not yet been identified. However, the possibility that $\mathrm{NH}$ preferentially affects posterior regions of the brain is of particular interest with regard to vision because visual brain areas are concentrated within the occipital lobe and extend anteriorly to the parietal and temporal lobes. Injury of the optic radiations following $\mathrm{NH}$ has also been reported with clear implications for visual processing [7].

The proposal that $\mathrm{NH}$ is associated with localized damage to posterior brain areas was not supported by a relatively large retrospective cohort study of infants with a history of $\mathrm{NH}(n=35)$, although all had intrauterine growth restriction and 4 had additional endocrine disorders [5]. This study reported diffuse, widespread injuries evident on magnetic resonance imaging obtained up to 6

Hypoglycaemia and Vision weeks after birth. Nevertheless, $29 \%$ of the cases reported in this study had a posterior pattern of brain injury, compared to only $6 \%$ with an anterior pattern.

\section{Neonatal Hypoglycaemia and Cortical Processing of Visual Information}

As might be expected from the finding that visual brain areas can be affected by $\mathrm{NH}$, visual impairments characteristic of abnormal cortical processing have been reported in babies and children who experienced severe or recurrent symptomatic $\mathrm{NH}(0.1-1.1 \mathrm{mmol} / \mathrm{L})[25,29]$. Tam et al. [20] conducted a retrospective case review of 45 infants who had experienced $\mathrm{NH}(<2.6 \mathrm{mmol} / \mathrm{L})$ and had also undergone diffusion-weighted brain imaging. Diffusion restriction within the occipital lobe was evident in $8(18 \%)$ infants, indicating potential injury to visual brain areas. No occipital lobe diffusion restriction was observed in babies who were imaged 6 days or more after experiencing $\mathrm{NH}$, suggesting that recovery from diffusion restriction may occur soon after $\mathrm{NH}$.

Despite the high rate of occipital lobe diffusion restriction reported by Tam et al. [20], only 2 of the 18 infants (11\%) for whom follow-up data were available were classified as having cortical visual loss when assessed at 4-8 months' corrected age. Both of these infants experienced $\mathrm{NH}$ for 2 days or more and had occipital lobe diffusion restriction on earlier scanning. One infant was diagnosed with cortical blindness indicative of bilateral occipital lobe injury and the other with homonymous hemianopia indicating a unilateral injury.

Visual evoked potentials (VEPs) were also measured in 20 of the infants studied by Tam et al. [20] at the corrected age of 4-8 months. Abnormal VEPs were reported in 11 infants (55\%). Details of the VEP protocol were not provided; however, as was the case for diffusion restriction, abnormal VEPs were not predictive of adverse visual outcomes.

The absence of a direct relationship between patterns of occipital lobe brain injury and visual deficits is also evident in a number of smaller case series and retrospective case reviews involving infants with $\mathrm{NH}$. For example, $\mathrm{Mu}-$ rakami et al. [25] found that 7 of 8 infants and children who had experienced $\mathrm{NH}(<1.1 \mathrm{mmol} / \mathrm{L})$ exhibited parieto-occipital lobe injuries, although only 3 of these developed impaired visual acuity. Similarly, Filan et al. [7] reported only 1 infant with visual impairment of 4 cases with $\mathrm{NH}(<1.5 \mathrm{mmol} / \mathrm{L})$ and occipital brain injury. Burns et al. [5] found a reasonably consistent association between 
posterior brain injury and visual deficits (11 of 35$)$ in their $\mathrm{NH}$ cohort (median blood glucose concentration: 1.0 $\mathrm{mmol} / \mathrm{L}$ ) when assessed at a minimum age of 18 months; however, formal vision testing was not conducted, so vision problems may have been under- or overestimated. They mention that although the majority of children with visual deficits incurred posterior cortex and white matter injury, some infants with severe occipital injuries did not show signs of vision problems. Visual deficits included strabismus ( 2 of 34 ), visual field defects ( 2 of 34 ), cortical visual impairment (2 of 34 ), abnormal visual attention and tracking (1 of 34), and difficulties with visuospatial activities (1 of 34). Yalnizoglu et al. [21] reported that only 4 of 10 children who suffered either occipital or occipitoparietal brain injury developed visual impairment. Finally, a report by Karimzadeh et al. [23] of 27 children with a history of symptomatic $\mathrm{NH}$ demonstrated that 12 of the 22 children who had occipital and parieto-occipital involvement on neuroimaging developed vision loss when assessed at the mean age of 3.5 years.

In summary, evidence for a direct and specific effect of $\mathrm{NH}$ on the integrity of the cortical and white matter pathways involved in vision is mixed. There also appears to be limited association between the presence of posterior brain injury and later visual function in studies of infants who experienced $\mathrm{NH}$. At least 3 non-mutually exclusive explanations could account for this dissociation. Firstly, although the methods used for visual assessment are typically not described, the testing was often conducted at a young age when accurate assessment of visual function is challenging [30]. Hu et al. [31] demonstrated that even VEP measurements are difficult to interpret in neonates, showing that although all 15 infants with $\mathrm{NH}$ and posterior brain injury tested had abnormal VEP waveforms, 6 of 11 healthy control infants also had abnormal VEP findings. Due to the difficulty in measuring visual function in infants, higherlevel deficits such as agnosia resulting from damage to extrastriate brain areas as well as more subtle visual field or contrast sensitivity losses may have been present but not detected in studies to date. Providing some support for this theory are reports that experimentally induced hypoglycaemia (maintaining a blood glucose concentration of 2.5 $\mathrm{mmol} / \mathrm{L}$ for $1 \mathrm{~h}$ ) in healthy adults does not affect clinical measures of visual acuity or stereopsis, but does impact on spatial contrast sensitivity and neuropsychological tests targeting higher-level visual processing and attention [32].

Secondly, NH may be associated with brain injury early in life, but the visual cortex is highly plastic during infancy and early childhood. It is conceivable that neural plasticity allows the remaining visual areas to compensate for minor brain injuries associated with $\mathrm{NH}$ [33]. Furthermore, both diffusion and structural MR data suggest that recovery of occipital regions from the effects of $\mathrm{NH}$ is possible over a period of weeks or months, indicating that $\mathrm{NH}$ may not permanently damage the occipital lobe in all cases [20,34].

Thirdly, deficits in vision resulting from early disruption to the visual system may not become apparent until later in development. Due to a lack of studies involving older children, it is not known whether abnormal visual cortex function early in development can result in abnormal visual development later in life.

\section{Prospective Studies on Neonatal Hypoglycaemia and Vision}

The majority of the studies described above have used retrospective case series designs to investigate the effect of $\mathrm{NH}$ on the eye and brain. However, a recent prospective follow-up study of 4042 -year-old children born at risk of $\mathrm{NH}$, the Children with Hypolgycaemia and Their Later Development (CHYLD) Study [4], has provided new data on the effects of mild-to-moderate treated $\mathrm{NH}$ on visual development. These infants underwent a detailed ophthalmic vision screening (visual acuity, stereopsis, red reflex, eye alignment, refractive error) and a measurement of global motion perception, a function of the dorsal visual cortical processing stream that may be particularly vulnerable to neurodevelopmental risk factors [35]. Two composite scores were generated relating specifically to vision. The first was a vision impairment score that captured ocular and vision problems. The second was a refractive error score that captured clinically significant refractive errors (hyperopia greater than or equal to $+4.00 \mathrm{dpt}$, myopia less than or equal to $-1.00 \mathrm{dpt}$, and astigmatism less than or equal to $-1.50 \mathrm{dpt}$ in any axis and anisometropia greater than or equal to $3.00 \mathrm{dpt}$ ). Global motion perception was measured using a motion coherence task, which assessed the ability to tolerate noise in an otherwise coherently moving dot field (a motion coherence threshold) [36].

Of the 404 children assessed, 216 experienced NH. Of the children who experienced NH, 152 (70\%) had mildto-moderate $\mathrm{NH}$ (blood glucose concentration of 2-2.6 $\mathrm{mmol} / \mathrm{L})$ and $64(30 \%)$ had at least one severe episode of $\mathrm{NH}$ (blood glucose concentration $<2 \mathrm{mmol} / \mathrm{L}$ ). No differences in vision impairment, refractive error, or global motion perception were found between the children who did and did not experience $\mathrm{NH}$, suggesting that short periods of primarily mild-to-moderate $\mathrm{NH}$ do not affect visual development at age 2 years.
Paudel et al. 
The prevalence of clinically significant refractive error within the cohort was $8 \%$ for the hypoglycaemic group and $11 \%$ for the non-hypoglycaemic group [4]. This rate was slightly higher than one of the previous $\mathrm{NH}$ studies that included refractive error measurements (2\%) [6] and considerably lower than the other (22\%) [23]. It should be noted that a non-cycloplegic refraction was conducted in the CHYLD study participants [4] that could have underestimated the prevalence of refractive error. Furthermore, all of the children enrolled in the CHYLD study who experienced $\mathrm{NH}$ were treated with the goal of keeping blood glucose concentrations $\geq 2.6 \mathrm{mmol} / \mathrm{L}$. Therefore, the hypoglycaemia experienced was generally mild to moderate $(2-2.6 \mathrm{mmol} / \mathrm{L})$, unlike the majority of previous studies that included children who experienced severe hypoglycaemia $(<2 \mathrm{mmol} / \mathrm{L})$. None of the children who experienced hypoglycaemia in the CHYLD study were blind (defined as visual acuity of $\geq 1.40$ logarithm of minimum angle of resolution $\sim 20 / 500$ Snellen equivalent), unlike some previous studies [20,21]. It is possible that effective treatment as soon as children were diagnosed with $\mathrm{NH}$ may have reduced the potential impact of $\mathrm{NH}$ on visual function. Results from a second follow-up of the CHYLD study at 4.5 years of age are awaited.

\section{Conclusion}

Current evidence suggests that severe and prolonged $\mathrm{NH}$ can be associated with injury of brain areas involved in visual processing, although the effect of these injuries on later visual function is currently unclear. This may in part be due to the difficulty of testing vision in young children. Furthermore, the fact that NH is frequently accompanied by comorbid conditions that can also impair neurological function complicates interpretation of the caseseries and case-review studies that constitute much of the current literature. Follow-up studies of randomized trials may help to isolate the effects of $\mathrm{NH}$ from those of other related conditions. At present, there are no consistently reported effects of severe $\mathrm{NH}$ on ocular development or eye alignment. Further, treated mild-moderate $\mathrm{NH}$ does not appear to affect visual function at 2 years of age [4]. However, the effects of abnormal visual experience early in life may only become apparent in late-to-middle childhood. It remains to be seen whether mild-moderate $\mathrm{NH}$ has an impact on visual function after preschool age.

\section{Acknowledgement}

This work was supported by grants from the Eunice Kennedy Shriver National Institute of Child Health and Human Development (R01HD069622), the Health Research Council of New Zealand (10-399), and the Auckland Medical Research Foundation (1110009). N.P. was supported by an Auckland Medical Research Foundation Doctoral Scholarship and New Zealand Association of Optometrists scholarship.

\section{Disclosure Statement}

The authors declare no conflicts of interest.

\section{References}

1 Hay WW, Raju TN, Higgins RD, Kalhan SC, Devaskar SU: Knowledge gaps and research needs for understanding and treating neonatal hypoglycemia: workshop report from Eunice Kennedy Shriver National Institute of Child Health and Human Development. J Pediatr 2009;155:612-617.

2 Adamkin DH, Polin R: Neonatal hypoglycemia: is 60 the new 40 ? The questions remain the same. J Perinatol 2016;36:10-12.

3 Stanley CA, Rozance PJ, Thornton PS, Leon DD, Harris DE, Haymond MW, et al: Re-evaluating "transitional neonatal hypoglycemia": mechanism and implications for management. J Pediatr 2015;166:1520-1525.

4 McKinlay CJ, Alsweiler JM, Ansell JM, Anstice NS, Chase JG, Gamble GD, et al: Neonatal glycemia and neurodevelopmental outcomes at 2 years. N Engl J Med 2015;373 $1507-1518$
5 Burns CM, Rutherford MA, Boardman JP, Cowan FM: Patterns of cerebral injury and neurodevelopmental outcomes after symptomatic neonatal hypoglycemia. Pediatrics 2008;122:65-74.

6 Koivisto M, Blanco-Sequeiros M, Krause U: Neonatal symptomatic and asymptomatic hypoglycaemia: a follow-up study of 151 children. Dev Med Child Neurol 1972;14:603614.

7 Filan PM, Inder TE, Cameron FJ, Kean MJ, Hunt RW: Neonatal hypoglycemia and occipital cerebral injury. J Pediatr 2006;148: 552-555.

8 McKinna AJ: Neonatal hypoglycemia - some ophthalmic observations. Can J Ophthalmol 1966;1:56-59.

9 Merin S, Crawford JS: Hypoglycemia and infantile cataract. Arch Ophthalmol 1971;86: 495-498.
10 Chylack LT: Mechanism of "hypoglycemic" cataract formation in the rat lens. I. The role of hexokinase instability. Invest Ophthalmol Vis Sci 1975; 14:746-755.

11 Rahi JS, Dezateux C: Congenital and infantile cataract in the United Kingdom: underlying or associated factors. Investig Ophthalmol Vis Sci 2000;41:2108-2114.

12 Prakalapakorn SG, Rasmussen SA, Lambert SR, Honein MA: Assessment of risk factors for infantile cataracts using a case-control study: National Birth Defects Prevention Study, 2000-2004. Ophthalmology 2010;117: 1500-1505.

13 Margalith D, Jan JE, McCormick AQ, Tze WJ, Lapointe J: Clinical spectrum of congenital optic nerve hypoplasia: review of 51 patients. Dev Med Child Neurol 1984;26:311-322. 
14 Skarf B, Hoyt CS: Optic nerve hypoplasia in children. Association with anomalies of the endocrine and CNS. Arch Ophthalmol 1984; 102:62-67.

15 Tornqvist K, Ericsson A, Källén B: Optic nerve hypoplasia: risk factors and epidemiology. Acta Ophthalmol Scand 2002;80:300304.

16 Fielder AR, Crawley LA: Disorders of vision; in Levene MI, Chervenak FA (eds): Fetal and Neonatal Neurology and Neurosurgery, ed 4. London, Churchill Livingstone, 2009, pp 743-768.

17 Petersen RA, Walton DS: Optic nerve hypoplasia with good visual acuity and visual field defects: a study of children of diabetic mothers. Arch Ophthalmol 1977;95:254-258.

18 Patel L, McNally RJQ, Harrison E, Lloyd IC, Clayton PE: Geographical distribution of optic nerve hypoplasia and septo-optic dysplasia in northwest England. J Pediatr 2006;148:8588.

19 Harris DL, Weston PJ, Harding JE: Incidence of neonatal hypoglycemia in babies identified as at risk. J Pediatr 2012;161:787-791.

20 Tam EWY, Widjaja E, Blaser SI, MacGregor DL, Satodia P, Moore AM: Occipital lobe injury and cortical visual outcomes after neonatal hypoglycemia. Pediatrics 2008; 122 :507512.

21 Yalnizoglu D, Haliloglu G, Turanli G, Cila A, Topcu M: Neurologic outcome in patients with MRI pattern of damage typical for neonatal hypoglycemia. Brain Dev 2007;29:285292.
22 Scheie H, Rubenstein R, Albert D: Congenital glaucoma and other ocular abnormalities with idiopathic infantile hypoglycemia. J Pediatr Ophthalmol Strabismus 1964;1:45-47.

23 Karimzadeh P, Tabarestani S, Ghofrani M: Hypoglycemia-occipital syndrome: a specific neurologic syndrome following neonatal hypoglycemia? J Child Neurol 2011;26:152-159.

24 Fotouhi A, Hashemi H, Khabazkhoob M, Mohammad K: The prevalence of refractive errors among schoolchildren in Dezful, Iran. Br J Ophthalmol 2007;91:287-292.

25 Murakami Y, Yamashita Y, Matsuishi T, Utsunomiya $\mathrm{H}$, Okudera T, Hashimoto T: Cranial MRI of neurologically impaired children suffering from neonatal hypoglycaemia. Pediatr Radiol 1999;29:23-27.

26 Caraballo RH, Sakr D, Mozzi M, Guerrero A, Adi JN, Cersósimo RO, Fejerman N: Symptomatic occipital lobe epilepsy following neonatal hypoglycemia. Pediatr Neurol 2004;31: 24-29.

27 Wang SM, Yang CS, Hou Y, Ma XW, Feng ZC, Liao YZ: Perinatal occipital lobe injury in children: analysis of twenty-one cases. Pediatr Neurol 2012;47:443-447.

28 Tam EW, Haeusslein LA, Bonifacio SL, Glass HC, Rogers EE, Jeremy RJ, et al: Hypoglycemia is associated with increased risk for brain injury and adverse neurodevelopmental outcome in neonates at risk for encephalopathy. J Pediatr 2012;161:88-93.

29 Alkalay AL, Flores-Sarnat L, Sarnat HB, Moser FG, Simmons CF: Brain imaging findings in neonatal hypoglycemia: case report and review of 23 cases. Clin Pediatr 2005;44:783790.
30 Trager MJ, Dirani M, Fan Q, Gazzard G, Selvaraj $P$, Chia $A$, et al: Testability of vision and refraction in preschoolers: the strabismus, amblyopia, and refractive error study in Singaporean children. Am J Ophthalmol 2009; 148:235-241.

31 Hu L, Gu Q, Zhu Z, Yang C, Chen C, Cao Y, et al: Flash visual evoked potentials are not specific enough to identify parieto-occipital lobe involvement in term neonates after significant hypoglycaemia. Acta Paediatr 2014 103:e329-e333.

32 McCrimmon RJ, Deary IJ, Huntly BJ, MacLeod KJ, Frier BM: Visual information processing during controlled hypoglycaemia in humans. Brain 1996;119:1277-1287.

33 Slotnick SD, Moo LR, Krauss G, Hart JJ: Large-scale cortical displacement of a human retinotopic map. Neuroreport 2001;13:41-46.

34 Kinnala A, Rikalainen H, Lapinleimu H, Parkkola R, Kormano M, Kero P: Cerebral magnetic resonance imaging and ultrasonography findings after neonatal hypoglycemia. Pediatrics 1999;103:724-729.

35 Braddick O, Atkinson J, Wattam-Bell J: Normal and anomalous development of visual motion processing: motion coherence and "dorsal-stream vulnerability". Neuropsychologia 2003;41:1769-1784.

36 Newsome W, Pare E: A selective impairment of motion perception following lesions of the middle temporal visual area (MT). J Neurosci 1988;8:2201-2211. 